Journal of Social Sciences 6 (3): 333-339, 2010

ISSN 1549-3652

(C) 2010 Science Publications

\title{
Achievement Motivation and Self-Efficacy in Relation to Adjustment among University Students
}

\author{
Habibah Elias, Nooreen Noordin and Rahil Hj. Mahyuddin \\ Department of Educational Foundations, Faculty of Educational Studies, \\ University Putra Malaysia, Serdang, Selangor, Malaysia
}

\begin{abstract}
Problem statement: University students' adjustment to the campus environment is regarded as an important factor in predicting university outcomes. Studies have shown that students who do not adjust themselves well, have left the university even before graduation. Approach: A study was conducted to examine some psychological characteristics of university students which may have bearing on students' adjustment in university environment. How students adjust themselves especially in the initial years at university may have impact on how successful they will be in tertiary education. An on line survey was conducted on 178 students from junior to senior students enrolled in education courses in a university in Malaysia. Achievement motivation, self-efficacy and student adjustment were measured using questionnaires available on-line. Results: The results showed that overall the students' level of adjustment was moderate $(\mathrm{M}=5.05, \mathrm{SD}=0.31)$ suggesting that they are facing some problems in adjusting to the campus environment. The senior students were better adjusted $(\mathrm{M}=5.12, \mathrm{SD}=0.32)$ compared to the junior students $(\mathrm{M}=4.95, \mathrm{SD}=0.27), \mathrm{t}(177)=-3.66$, $\mathrm{p}=0.001)$. Achievement motivation and self-efficacy range from moderate $(\mathrm{M}=3.17, \mathrm{SD}=0.43)$ to high levels $(M=5.15, S D=0.78)$ indicating that they have the potentials to succeed. The three variables namely adjustment, achievement motivation and self-efficacy were found to be correlated positively with one another. Conclusion: The implications of the findings are discussed in terms of teaching and learning in higher education. Recommendations include providing the relevant courses and counseling sessions especially for the first year students.
\end{abstract}

Key word: Students' adjustment, achievement motivation, self-efficacy

\section{INTRODUCTION}

Psychosocial factors have been proven by research to have influence on students' level of adjustment to university campus life. One of the goals of tertiary education is to produce good quality students with well adjusted personality. This is in line with Malaysia's Educational Philosophy which is 'The Development of the individuals' potential in a holistic and integrated manner, to produce individuals who are intellectually, spiritually, emotionally and physically balanced and harmonious, based on a firm belief in and devotion to God (Nooreen et al., 2009).

The increase in the number of universities and enrolment of students for the last three decades in Malaysia shows that there is a need to understand what constitute a successful transition to campus life. After secondary education, students may have difficulty in understanding what university life can offer them. They may have some ideas of campus life, but to have an understanding of what academic or social life in the real situation may not be fulfilled yet.

The first year in university can be a time filled with new and exciting experience. It can also be a challenging experience to most students. Studies have shown that the better adjusted students are to their academic environment, the better will be their academic performance (Lent et al., 2009). The transition period from secondary school to university can be difficult for some students especially after going through the dependent stage at home or in school where they have to abide by the rules laid down by parents and the school. From their perspective, university is a time when these controls disappear and they become independent just like adults. Previous research have shown that the transition period from secondary to tertiary education is a crucial period that set the stage for students' success or failure in the later stage of university life (Gall et al., 2000; Hutardo and Carter, 1997).

Corresponding Author: Habibah Elias, Department of Educational Foundations, Faculty of Educational Studies, University Putra Malaysia Serdang, Selangor, Malaysia 


\section{J. Social Sci., 6 (3): 333-339, 2010}

The transition period can be stressful for some students (Perry et al., 2001) and many students even withdraw before graduation (Tinto, 1996). This phenomenon could be due to the variety of challenges faced by students especially in their early years in university. The challenges include forming new relationships, adjusting existing relationships with parents and family (living far away from home) and learning new strategies in the new academic environment. They need to learn to be independent and if they failed to cope with the new challenges, they may have to leave the university even before they graduate.

Among the variables studied by previous researchers on adjustment of students, were selfefficacy and achievement motivation of students. Selfefficacy refers to the beliefs about one's capabilities to learn or perform behaviors at designated levels (Bandura, 1997). Achievement motivation is a construct which refers to the desire to do well in order to attain an inner feeling of personal accomplishment (McClelland, 1987).

A study conducted by Lent et al. (2009) on 252 students at a university in Northern Portugal, found that self-efficacy and environmental support were predictive of goal progress and academic adjustment. Students reported gains in their academic functioning when they possess stronger self-efficacy and environmental support.

A study conducted by Hirose et al. (1999) on the effects of self-efficacy of adjustment to college among 1,385 Japanese students, found that the three subscales for self-efficacy: Judgmental ability based on objective information, self-controlled persistence of activity and self-adjustment in human relations are basic competencies necessary for college adjustment. They found significant differences between well adjusted and poorly adjusted groups in terms of the three scales of self-efficacy.

Another study conducted by Peterson et al. (2009) on 194 first year students who are economically and educationally disadvantaged found that psychosocial factors (academic motivation, self-esteem, perceived stress and perceived academic overload) explained about $59 \%$ of the variance in students' adjustment and $20 \%$ of variance in their academic performance.

When a person is confronted with difficulties and he believes in himself as competent, this can promote motivation. On the other hand beliefs about oneself as ineffective when confronted with difficulties can undermine motivation (Reeve et al., 2004). In a study conducted by Malmberg and Little (2007) on 5th and 6th Grade children, they found differences in motivation among the strivers and the disengaged students. The strivers motivational profile revealed a high level of intrinsic motivation and extrinsic motivation. Their achievement and school well being were generally at the normative level. For the disengaged, they displayed low level of intrinsic and extrinsic motivation, achievement level moderate and school well being very low. For the Challenged group, the low levels of intrinsic motivation coupled with the high levels of extrinsic motivation are consistent with the maladaptive pattern that is they show the lowest levels of school well being. The above findings indicate the importance of student motivation in their learning environment.

Given the above background on students' adjustment in university, it is the intention of this study to examine the level of several psychosocial variables namely adjustment, self-efficacy and achievement motivation among students in a Malaysian University. It is believed that the above variables may affect adjustment and subsequent success in university life. Findings of the study will help to determine the relationship between the psychosocial variables and student's level of adjustment.

\section{MATERIALS AND METHODS}

The study employed the descriptive survey method to describe the levels of the variables investigated, namely, students' adjustment, achievement motivation and self-efficacy.

Sample: The sample of the study comprised of 178 students attending education courses in the Faculty of Educational Studies in University Putra Malaysia.

Students were invited to answer the questionnaire which was available on-line during their free time. Respondents comprised of 60 (33.7\%) science students and $118(66.3 \%)$ social Science students. They include the junior students (year one and year two) as well as the senior students (year three and year four).

Instrumentation: The study utilized questionnaires and instruments to measure psychosocial variables such as adjustment, self-efficacy and achievement motivation. Self-efficacy and achievement motivation were the independent variables and adjustment was the dependent variable. Specific instruments were administered to students on-line.

The instruments reliability levels were tested and findings revealed that the alpha values for the variables are as follows: Adjustment scale: 0.889, Self-efficacy scale: 0.892. Achievement motivation scale: 0.915 . 
The instruments used in the study were adapted from well-established instruments and the items for each instrument were validated by experts. The instruments used are as follows:

- Self-efficacy: Academic Efficacy of the Patterns of Adaptive Learning Survey (PALS) by Midgley et al. (1996) and Patrick et al. (1977)

- Achievement Motivation: Mehrabian and Bank (1978) Achievement Scale

- Adjustment Scale: Baker and Siryk (1999). Student Adaptation to College Questionnaire Manual. Los Angeles: Western psychological services

\section{RESULTS}

Socio-demographic characteristics: The socio demographic characteristics of the respondents are summarized in Table 1. Among the 178 respondents, 49 $(27.8 \%)$ were males and $127(72.2 \%)$ were females. They represent a young age group (mean age $=21.5$ ) with an age range of 18-25 years. The science students made up $33.7 \%$ of the respondents while $66.3 \%$ were the social science and Humanities students. Majority of the respondents came from families whose parents have primary and secondary education (fathers-73\%, mothers-79.2\%) while $47.8 \%$ of their parents have tertiary education (fathers-27\%, mothers-20.8\%). Majority of the respondents' parents received income less than RM1000 (47.2\%) while those in the RM1000RM2000 income bracket comprised of $21.3 \%$.

Table 1: Socio-demographic variables of participants $(\mathrm{N}=178)$

\begin{tabular}{lc}
\hline Socio demographic variables & Mean/frequencies (\%) \\
\hline Age & Mean = 21.5 \\
\hline Gender & \\
Male & $127(27.8)$ \\
Female & \\
Ethnic group & $137(77.8)$ \\
Malay & $19(10.8)$ \\
Chinese & $12(6.8)$ \\
Indian & \\
Program of study & $60(33.7)$ \\
Science & $118(66.3)$ \\
Social science and humanities & \\
Fathers' education status & $130(73.0)$ \\
Primary/secondary & $48(27)$ \\
Tertiary & \\
Mothers' education status & $141(79.2)$ \\
Primary/secondary & $37(20.8)$ \\
Tertiary & \\
Parents' income & $84(47.2)$ \\
<RM1000 & $38(21.2)$ \\
RM 1000-2000 & $26(14.6)$ \\
RM 2001-3000 & $22(12.3)$ \\
RM 3001-5000 & $8(4.5)$ \\
RM5001 & \\
\hline & \\
\hline &
\end{tabular}

Students' level of adjustment: Students' level of adjustment was measured by an adapted version of student adaptation to college questionnaire by Baker and Siryk (1999). The questionnaire comprised of 42 items with a scale of 1 (not related to me at all) to 9 (very much related to me). The scores were analyzed and divided into three categories which are: Low level of adjustment (0-197), moderate level of adjustment (198-278) and high level of adjustment (279 and above).

Table 2 shows students' level of adjustment in the university. The majority of students (64.4\%) have moderate level of adjustment. Only $12.9 \%$ of students showed high level of adjustment while another $22.6 \%$ were in the low category of adjustment.

As shown in Table 3, the items with high mean scores reflect the goals that they want to achieve in the near future. Item 4-" I know my goals at the university and what I want" has a mean score of 7.3 which shows their ambition to have a bright future knowing the goals that they have to achieve. This finding supports that of Tinto (1993) which emphasized that the level of educational and occupational goals is important in determining whether students will complete their tertiary education.

Students who are clear with their goals tend to have better adjustment since they know that they have to study really hard in order to achieve the goals and to follow the right direction.

The high mean scores for item 41 and 38 shows the students' level of satisfaction with their academic status and the academic staff at the university. These are aspects reflecting good adjustment. Another item which reflects good adjustment is item 3-"While at the university, I met and made as many friends as I liked". This shows that students are enjoying themselves getting along with others in campus.

On the other hand, respondents also showed low mean scores for items related to problems and challenges faced in the university. Items 33 and 27 reflect difficulties that they faced in academic study. Facing problems in preparing assignments and not getting good academic achievement equivalent to the amount of study done show that they are not able to adjust well to the campus study culture. Missing home and not getting along with roommates and thinking of quitting their studies indicate the difficulties students faced in the university environment. Items 15, 21 and 37 clearly show the problems of students who have difficulty in adjusting themselves to campus life.

Table 2: Levels of student adjustment in university

\begin{tabular}{lcc}
\hline Categories & Frequency & Percentage \\
\hline Low & 40 & 22.6 \\
Moderate & 114 & 64.4 \\
High & 23 & 12.9 \\
Total & 177 & 100.0 \\
\hline
\end{tabular}




\section{J. Social Sci., 6 (3): 333-339, 2010}

Table 3: Selected items from students' adjustment scale for university students

\begin{tabular}{llll}
\hline No. & Item & Min & SD \\
\hline 36 & Most of the things I am interested in are not relevant to the courses I am following at the university. & 7.73 & 2.19 \\
4 & I know my goals at the university and what I want. & 7.30 & 7.05 \\
20 & Lately, I have been thinking a lot whether to get help from the counseling unit at the university. & 6.92 & 1.76 \\
41 & I am quite satisfied with my academic status at the university. & 6.88 & 2.01 \\
3 & While at the university, I met and made as many friends as I liked. & 6.36 & 1.58 \\
38 & I am extremely satisfied with the lecturers who are teaching me. & 6.18 \\
8 & I failed to do well during the examination. & 3.66 & 3.95 \\
33 & I face a lot of problems when starting an assignment. & 3.51 & 2.28 \\
37 & Lately, I have been thinking a lot about quitting my studies for good. & 3.21 \\
19 & I am satisfied with the co-curriculum activities conducted at this university. & 3.21 & 1.92 \\
21 & I can get along with my roommates at the residential college or at the rented house. & 2.51 \\
15 & Missing my home and my family are the causes to the problems that I am facing now. & 2.36 \\
27 & I did not obtain a good academic achievement equivalent to the amount study done. & 1.84 \\
29 & At time, my mind is easily troubled. & 2.22 & 1.72 \\
\hline
\end{tabular}

Table 4: T-test on students' overall adjustment between senior and junior students

\begin{tabular}{lrllll}
\hline Variable & \multicolumn{1}{c}{$\mathrm{N}$} & $\mathrm{M}$ & $\mathrm{SD}$ & $\mathrm{t}$-value (2-talied) & Sig. (p-value) \\
\hline Junior & 69 & 4.95 & 0.27 & -3.52 & 0.001 \\
Senior & 108 & 5.11 & 0.32 & & \\
\hline
\end{tabular}

Table 5: Students' level of achievement motivation

\begin{tabular}{lcc}
\hline Categories & Frequency & Percentage \\
\hline Low & 6 & 3.4 \\
Moderate & 68 & 38.4 \\
High & 103 & 58.2 \\
Total & 177 & 100.0 \\
\hline
\end{tabular}

An independent t-test was conducted to compare the mean overall adjustment score for the senior students (Year 3 and 4) and the junior students (Year 1 and 2). Results in Table 4 showed that there was a significant difference in the mean overall adjustment score for Senior students $(\mathrm{M}=5.118, \mathrm{SD}=0.32)$ and Junior students $(M=4.95, \mathrm{SD}=0.27), \mathrm{t}(175)=-3.665$, $\mathrm{p}=0.001$. An inspection of the two means suggested that the senior students were better in their overall adjustment compared to the junior students. Given time and enough experience it is most likely that the students will adjust themselves to the various challenges in campus life (Hutardo and Carter, 1997).

Students' level of achievement motivation: The level of students' achievement motivation was measured by an adapted instrument from Mehrabian and Bank (1987) Achievement Scale. There questionnaire consisted of 22 items with a scale of 1(strongly disagree) to 4 (strongly agree).

Table 5 shows students' level of achievement motivation. The majority of respondents (58.2\%) showed high level of achievement motivation, while $38.4 \%$ were in the moderate category. Only $3.4 \%$ of students were in the low level of achievement motivation.
Table 6: Selected items from achievement motivation scale

\begin{tabular}{llll}
\hline No. & Items & Mean & SD \\
\hline 1 & I have high hopes and goals for myself & 3.55 & 0.72 \\
8 & I make an effort now for future gains. & 3.53 & 0.71 \\
3 & I strive to achieve my goals. & 3.51 & 0.70 \\
4 & I am interested to learn new things. & 3.49 & 0.70 \\
11 & $\quad$ I am satisfied with my current & 3.01 & 0.75 \\
& $\begin{array}{l}\text { achievement even though it is not } \\
\text { better than others. }\end{array}$ & & \\
13 & $\quad$ I like to study hard & 3.00 & 0.72 \\
21 & $\begin{array}{l}\text { I am annoyed when someone else } \\
\text { is better than me }\end{array}$ & 2.69 & 0.92 \\
14 & $\begin{array}{l}\text { I like to do normal and easy study } \\
\text { rather than hard ones. }\end{array}$ & 2.35 & 0.77 \\
15 & $\begin{array}{l}\text { I like to learn easy and fun games } \\
\text { rather than hard ones. }\end{array}$ & 2.17 & 0.77 \\
\end{tabular}

Table 7: Students' level of self-efficacy

\begin{tabular}{lcc}
\hline Categories & Frequency & Percentage \\
\hline Low & 3 & 1.7 \\
Moderate & 96 & 53.9 \\
High & 79 & 44.4 \\
Total & 178 & 100.0 \\
\hline
\end{tabular}

As shown in Table 6, items with high mean scores (1, 8, 3 and 4) indicate university students need to strive for future success to achieve goals which they have set. This finding is in line with the theory of achievement motivation which postulate that people with high need to achieve are future oriented, confident, responsible and have positive beliefs in themselves.

On the other hand, there are also students with low achievement motivation as shown by the low scores obtained in some of the items in Table 5. For instance items 11 and 15 indicate low level of achievement motivation as they are not willing to strive hard and contented with what they have achieved. The unwillingness to face challenges and finding easy way out shows that they are not willing to compete is a setback that they need to overcome. 
Table 8: Selected items from the self-efficacy scale

\begin{tabular}{|c|c|c|c|}
\hline No. & Item & Mean & SD \\
\hline 10 & When I find that many had failed the examination, I am more determined to succeed. & 5.72 & 1.15 \\
\hline 13 & I believe in the end I will succeed in mastering a subject that I do not understand now. & 5.70 & 1.08 \\
\hline 6 & I expect to show a good achievement in the class that I am following. & 5.57 & 1.06 \\
\hline 7 & I am confident I am able to master the skills taught in the classes I follow. & 5.56 & 0.98 \\
\hline 5 & I am confident that I am able to complete my assignment and test in the courses that I am takin & 5.54 & 1.06 \\
\hline 15 & I do not doubt in my ability to succeed in the examination. & 5.33 & 1.29 \\
\hline 4 & I am confident that I am able to understand the most complex material taught by my le & 5.08 & 1.22 \\
\hline 2 & I am confident I am able to understand the most difficult material from the reading material for the course I am follov & 4.97 & 1.28 \\
\hline
\end{tabular}

Table 9: Correlation analysis between student adjustment, achievement motivation and self-efficacy of students

\begin{tabular}{llll}
\hline Variables & $\begin{array}{l}\text { Student } \\
\text { adjustment }\end{array}$ & $\begin{array}{l}\text { Achievement } \\
\text { motivation }\end{array}$ & Self-efficacy \\
\hline Student adjustment & 1 & $0.170^{*}$ & $0.245^{* *}$ \\
Achievement motivation & $0.170^{*}$ & 1.000 & $0.442^{* *}$ \\
Self-Efficacy & $0.245^{* *}$ & $0.442^{* *}$ & 1.000 \\
\hline
\end{tabular}

*: Sig. at 0.05 level (2-tailed); **: Sig. at 0.01 level (2-tailed)

Students' self-efficacy: The level of students' selfefficacy was measured by an adapted version of Academic Efficacy of the Patterns of Adaptive Learning Survey by Midgley et al. (1996). The questionnaire comprised of 15 items with a scale of 1 (not true about me at all) to 7 (very much true of me).

Table 7 shows the level of students' self-efficacy in the university. The majority of students (53.9\%) in the study showed moderate level of self-efficacy. A considerable percentage of students $(44.4 \%)$ showed high level of self-efficacy while only a small percentage $(1.7 \%)$ of the students were in the low category of selfefficacy.

As shown in Table 8, generally the university students in the study show moderate and high levels of self-efficacy and are successful in coping and adapting to the new environment in the campus. The above items show that students are confident in their ability to perform well in the courses taken and they have positive self belief about themselves in handling difficult situations and challenges. Having a positive self-efficacy is an important trait that can contribute to future success. The finding supports Bandura (1997) conception on self-efficacy which partly determines the development of the basic self-management and interpersonal skills on which future careers are founded.

A further analysis was done to examine the relationship between the variables under study. The results of correlation analysis are shown in Table 9.

Table 9 shows the correlation analysis of student adjustment, achievement motivation and self-efficacy. Student adjustment has a positive and significant correlation with achievement motivation $(r=0.17$, $\mathrm{p}<0.05)$. Even though this correlation is rather weak, the tendency is for students who have strong achievement motivation are most likely to adjust themselves well in university. In order to adjust themselves in the academic environment they have to be strong in their willingness to strive hard in their studies, in addition to their future orientation and readiness to face challenges. Student adjustment is significantly correlated with student self-efficacy $(\mathrm{r}=0.245, \mathrm{p}<0.01)$. This indicates that students with a strong sense of self-efficacy tend to be better adjusted in the university environment. In order for students to adjust to the university campus life, they have to develop the confidence in their ability to achieve success in the courses that they have chosen. In addition a positive and significant correlation was also found between self-efficacy and achievement motivation $(\mathrm{r}=0.445, \mathrm{p}<0.01)$. This shows that students who are confident in themselves in achieving success in their studies tend to have the need to achieve excellence. Both these variables are related to student adjustment in university. The findings lend support to the research done by Pajares (1996) and Schunk (1995) who found significant correlations between the three variables.

\section{DISCUSSION}

The findings of the study showed that university students irrespective of their year of study generally have moderate levels of adjustment. However comparison between the senior and junior students shows there is a significant difference between their level of adjustment with senior students being better adjusted than the juniors. Students seem to have difficulties in their academic study and coping with the learning tasks. Their difficulties include studies, personal, emotional and social matters. The belief that at tertiary level students are matured enough to be able to cope with all kinds of challenges is not totally true. Findings from the present study show that in real life students do face a variety of problems and difficulties in their effort to adjust themselves in the university. The senior students tend to do better as they grow older and more matured compare to the junior students.

Findings from this study help to improve understanding on students' adjustment in university 
especially the new intake. There is a need to identify adjustment problems experienced by students and appropriate intervention programs should be planned for them. This is especially true for new students who may have problems in coping with the demands and challenges that can develop stress and tension in their campus life. Students who have low adjustment level and who are having difficulties with their studies should be given the appropriate counseling.

Academic advisors and faculty members should be more involved in the orientation programs for the freshmen to provide guidance on the adjustment skills that they need. Informal interactions with students should be encouraged in order to create greater intellectual integration in the campus. Student interactions with faculty members are necessary in order to avoid boredom and low levels of academic performance.

Senior students should be actively involved in helping new students as senior students can influence significantly the attachment and social adjustment of students (Hutardo and Carter, 1997). For instance in orientation programs, the seniors should be encouraged to become leaders, advisors and mentors to the new students. However the seniors need to be properly trained so that they can become effective advisors and mentors.

\section{CONCLUSION}

The study confirms that students in university do face problems in adjusting themselves at the university. Therefore serious attention need to be given to students who face problems in the first two years in university. In view of the findings, it is apparent that problems faced by students at the initial stage have to be addressed accordingly. Orientation programs and transition activities have to be geared to the needs of the students especially those who have difficulties in adjustment in the new environment. Coping skills and social support are some of the ways in which these new students can be assisted. With the right kind of guidance from the university management and students affairs division, adjustment to university can be a joy and not a problem anymore.

\section{REFERENCES}

Baker, R.W. and B. Siryk, 1999. Student adaptation to college questionnaire manual. WPS Test Report, Western Psychological Services, Los Angeles, pp: 1-8. http://portal.wpspublish.com/pdf/sacq.pdf
Bandura, A., 1997. Self-Efficacy: The Exercise of Control. 1st Edn., Worth Publishers, New York, ISBN: 13: 978-0716728504, pp: 604.

Gall, T.L., D.R. Evans and S. Bellarose, 2000. Transition to first-year University: Patterns of change in adjustment across life domains. J. Social Clin. Psychol., 19: 544-567.

Hirose, E.L., S. Wada and H. Watanabe, 1999. Effects of self-efficacy on adjustment to college. Jap. Psychol. Res., 41: 163-172.

Hutardo, S. and D.F. Carter, 1997. Effects of college transition and perceptions of the campus racial climate on Latino College students' sense of belonging. Sociol. Educ., 70: 324-345.

Lent, R.W., M.C. Taveira, H.B. Sheu and D. Singley, 2009. Social cognitive predictors of academic adjustment and life satisfaction in Portuguese college students: A longitudinal analysis. J. Vocat. Behav., 74: 190-198.

Malmberg, L.E. and T.D. Little, 2007. Profiles of ability, effort and difficulty: Relationships with worldviews, motivation and adjustment. Learn. Instruct., 17: 739-754.

McClelland, D.C., 1987. Human Motivation. Scott Foresman and Co., London, pp: 663.

Mehrabian, A. and L. Bank, 1978. A questionnaire of individual differences in achieving tendency. Educ. Psychol. Measur., 38: 475-478.

Midgley, C., M.L. Maehr, L. Hicks, R.W. Roeser and T. Urdan et al., 1996. Manual for the Patterns of Adaptive Learning Scale (PALS). University of Michigan, Ann Arbor, pp: 74.

Nooreen, N., E. Habibah and M. Rahil, 2009. Understanding psychosocial behavioral patterns: Factors and problems in school to university transition. MASAUM J. Soc. Sci., 1: 42-56.

Pajares, F., 1996. Self-efficacy beliefs, in academic setting. Rev. Educ. Res., 66: 534-578.

Patrick, H., L. Hicks and A.M. Ryan, 1997. Relations of perceived social efficacy and social goal pursuit to self efficacy for academic work. J. Early Adolesc., 17: 109-128.

Perry, R.P., S. Hladkyi, R.H. Pekrun and S.T. Pelletier, 2001. Academic control and action control in the achievement of college students: A longitudinal field study. J. Educ. Psychol., 93: 776-389.

Peterson, I., J. Louw and K. Dumont, 2009. Adjustment to university and academic performance among disadvantaged students in South Africa. Educ. Psychol., 29: 99-115. 
Reeve, J., E. Deci and R.M. Ryan, 2004. SelfDetermination Theory: A Dialectical Framework for Understanding Sociocultural Influences on Student Motivation. In: Research on Sociocultural Influences on Motivation and Learning, McInerney, D.M. and S. van Etten (Eds.)., Vol. 4, Information Age, Greenwich, CT., pp: 31-60.

Schunk, D.H., 1995. Self-efficacy in Education and Instruction. In: Self-Efficacy, Adaptation and Adjustment: Theory, Research and Application, Maddux, J.E. (Ed.). Plenum Press, New York, pp: 281-303.
Tinto, V., 1993. Leaving College: Rethinking the Causes and Cures of Student Attrition. 2nd Edn., University of Chicago Press, Chicago, pp: 312.

Tinto, V., 1996. Reconstructing the first year of college. Plann. Higher Educ., 25: 1-6. 